\title{
Jozef M. van Brabant replies:
}

While I can sympathize with the author's chagrin about my rather negative review of her book, I do not wish to enter into a detailed rebuttal for her observations are as flawed as is her book. The interested reader can simply make his/her own comparison and adjudicate whether I am less than a "careful, well-informed and serious reviewer." Just a few brief observations should suffice.

First, I do not make any inference on the author's competence in anthropology or ethnography. I am reasonably ignorant in those areas; hence the "presumably" in my review. I maintain, however, that if the author's brand of anthropology-ethnography, after a decade of research and over 1750 interviews, is the best that her area of expertise can offer to understanding the transformations in eastern Europe, it has little of interest to - at least this economist.

Second, I take my task of reviewer seriously: Provide a critical overview of what the book has to offer, its weaknesses, and its strengths. I do so no matter the publicity and controversy generated. Would the author have welcomed only another variant of the positive blurbs and reviews she cites, ignoring of course the negative critiques?

Third, the value of a book lies in its accuracy not in its numerous attributes (references, interviewees, data collections, etc). The author may find my nitpicking beyond the bounds of decency, but how can she then imply that I am "uninformed" and did not read the book carefully? The numerous inaccuracies that I flagged up, not to mention the many others I annotated, made me uneasy, putting it mildly, about her product.

Finally, the author would have done at least the economic profession a real service by focusing chiefly on chapter 4 of the book - the myriad of abuses she observes in the nexus US Government, USAID, HIID, and the various Russian "clients." That would necessarily have required positioning the inquiry within the interstices of economics and politics in the context of the élite revolving-door politics so typical of the higher echelons of the U.S. government. She might even have come up with a broader theoretical framework. The one in the book (and later elaborations) around the Chubais clan, for example, is neither illuminating nor compelling.

\section{Jozef M. van Brabant}

DC2 2150

New York, NY 10163-0020 